\title{
1
}

\section{Becoming Europeans: A History of the European Schools}

Educated side by side, untroubled from infancy by divisive prejudices, acquainted with all that is great and good in the different cultures, it will be borne in upon them as they mature that they belong together. Without ceasing to look to their own lands with love and pride, they will become in mind Europeans, schooled and ready to complete and consolidate the work of their fathers before them, to bring into being a united and thriving Europe. (Jean Monnet 1953)

The European Schools were founded nearly sixty years ago in the aftermath of World War Two, with the first being established in Luxembourg, which, together with Brussels and Strasbourg, is one of the three official capitals of the European Union and the seat of the European Court of Justice. There are now fourteen schools in seven countries serving over 25,000 students. Designed for the children of European Union employees, they have a special legal status within Europe and use a particular model of curriculum and assessment that in many ways represents a hybrid of the different European educational models in existence. In this book we examine the role, function and status of these European schools. 
It is customary to speak of a group of schools as a system and indeed there is a great deal of sense in this for the reasons we explain below. However, describing education as a system risks ignoring the core of that activity, namely, that it is a series of profoundly personal acts of learning. Thus from the outset, any consideration of this education system also needs to take into account the tension between the instinctive drive to learn and the systematic attempt to organize and control it. The root of this tension lies in the difference between the basic demand for access to learning opportunities for the satisfaction of needs (emotional, spiritual, material and intellectual) and the selection and control processes that education systems undertake.

Education systems change over time and experience alterations to both their internal and external structures and relations. Whether change occurs or not depends on the capacity within the system as well as the condition of the change-catalyst or set of reforms. And these in turn are structured in particular ways, which determines their ability to act as change-agents. Certain types of catalyst are more likely to induce change in a system than others; for example, changes of personnel (caused naturally through retirements and deaths or by people in powerful positions within the system exercising their authority), new policies, events in nature, external interventions, new arrays of resources, new arrangements of roles and functions within a system, new financial settlements and so forth. In short, some of these change-catalysts are more powerful than others, or at least have the potential to be more powerful. Even here though, the capacity of the catalyst to effect change within a system cannot guarantee or determine whether change actually occurs. We can see this most clearly in some of the reform processes undertaken in the European School System, such as the 2009 reforms which focused on opening up the system and the European Baccalaureate to other students, governance issues in the system, and cost-sharing amongst the member states. Any reform or change process does not guarantee or determine the degree of change within the system, how long lasting the reform is and any unexpected consequences that occur. Furthermore, some types of change-catalyst are more likely to be successful in inducing change within the system than others. This is not only because some interventions in education systems are more powerful than others but also because their 
capacity to induce change fits better the change mechanism within the system being reformed.

For example, in a system that has a high level of command structure between the coordinating body and its constituent parts, a policy for change at the classroom level that is underpinned by a strong system of rewards and sanctions is likely to be successful in inducing change at this level. This is in contrast to systems which grant greater degrees of autonomy to their teachers, and consequently the same change mechanism may have less chance of succeeding. Extra-national change-agents work in the same way and the Organisation for Economic Cooperation and Development's system of international assessment (known as the Programme for International Student Assessment) is an example of this. What these globalizing bodies, such as the OECD, are attempting to do is establish a form of global panopticism where the activities of the various national and cross-national systems are made visible to a supranational body, with the consequence that all parts of the system are visible from one single point. However, what this needs is a single surface of comparison or at least a comparative mechanism that can do this, so that enough people have confidence in it for it to be considered useful. This fundamentally applies to a particular education system, such as the European School System, which is the focus of this book.

What we have been doing here is categorizing the European School System as a set of institutions and relations between its parts, and even perhaps as a coordinating body for a number of sub-systems, which have a particular relation to the central authority and a particular position within it. However, this doesn't mean that relations between the central authority and the schools, and in addition, between the system and other bodies external to it, remain the same over time. These relations may change for a number of possible reasons, for example, the invention of new ideas, natural progression, contradictions as historically accumulating structural tensions between open activity systems (cf. Engeström 2001) and so forth.

It is fairly easy to understand an education system as a coordinating body that directs a number of sub-units, so that if the central authority demands action of a particular type, then these subsidiary bodies will implement its directives. The cohering element in the notion of a system 
being used here is that one body commands a series of other bodies, though all of them are considered to be elements of a system. However, it is rare for any actual system to function in this way. Within the system the extent and type of power that the coordinating body can exercise over the other elements may be exercised in different ways. Thus, a system's coordinating body may have less or more direct relations with different parts of the system. Indeed, it may be that some of these relations become so attenuated that it becomes harder to include them in the system.

Furthermore, systems have internal rules, that is, their elements are arranged in particular ways. Traditional systems have a high degree of specialization; a clearly defined division of labour; the distribution of official tasks within the organization; a hierarchical structure of authority with clearly defined areas of responsibility; formal rules which regulate the operation of the organization; a written administration; a clear separation between what is official and what is personal; and the recruitment of personnel on the basis of ability and technical knowledge. All of this is relevant to the European School System, so long as it is understood that this system was set up with a particular purpose in mind and a set of accountability relations to a central authority, the European Union Commission, which means that its bureaucratic structures are particular to that system.

However, regardless of how we understand the notion of a system, any change to it is always a transformation of the status quo, to a greater or lesser degree. Therefore, we need to understand how those systems and curricula are and have been structured. What this means is that the same programme of reform delivered in different systems of education is likely to have different effects on the different elements of the system and will have different histories within the system. In the first instance then we are concerned to plot the history of this almost unique education system.

\section{A History of the European School System}

The European School System was formed in October 1953 in Luxembourg, and was the initiative of members of the European Coal and Steel Community and the Luxembourg Government. The six different 
governments of the Community and their respective ministries of education worked together to forge a system that educated pupils with different mother tongue languages and different nationalities. In April 1957, the signing of the Protocol made the Luxembourg school the first official European school. The first European Baccalaureate was awarded in July 1959 and the qualification was recognised as fulfilling basic entry requirements by all the universities of the member states. The success of this educational experiment encouraged the European Economic Community (and the European Atomic Energy Commission), both of which were eventually taken over by the executive institutions of the EEC, to persuade the authorities to establish other European schools at their various centres of government.

At the time of writing there are fourteen European schools in seven different countries (see Table 1.1).

In addition, there are twelve accredited Category II and III European schools with more at the planning stage.

The European Schools Network has its own rules in terms of enrolment, funding and management, as well as its own curriculum. The system was first created as an instrument to meet the educational needs of the children of the civil servants working in Luxembourg for the then

Table 1.1 Category I European Schools

\begin{tabular}{llll}
\hline School & Member state & Creation & First Baccalaureate \\
\hline Luxembourg I & Luxembourg & 1953 & 1959 \\
Brussels I & Belgium & 1958 & 1964 \\
Mol/Geel & Belgium & 1960 & 1966 \\
Varese & Italy & 1960 & 1965 \\
Karlsruhe & Germany & 1962 & 1968 \\
Bergen & The Netherlands & 1963 & 1971 \\
Brussels II & Belgium & 1974 & 1982 \\
Munich & Germany & 1977 & 1984 \\
Culham & United Kingdom & 1978 & 1982 \\
Brussels III & Belgium & 1999 & 2001 \\
Alicante & Spain & 2002 & 2006 \\
Frankfurt & Germany & 2002 & 2006 \\
Luxembourg II & Luxembourg & 2004 & 2013 \\
Brussels IV & Belgium & 2007 & 2017 \\
\hline
\end{tabular}

Source: Office of the Secretary General of the European Schools (2017) 
newly formed European Union. The different stakeholders, i.e. parents, institution officials, civil servants and policy-makers, reached an agreement that these children should have the opportunity to be educated in their mother tongue, as well as having the same standard of education as their national classmates in their home countries. Two-thirds of the funding comes from the institutions of the European Union.

The system has remained almost unchanged for nearly six decades, maintaining an enrolment policy that gives priority to children of European Union civil servants. Moreover, from the outset the system has offered its own school certificate, the European Baccalaureate, which is recognised in law by all the universities in the European Union (cf. Office of the Secretary General of the European Schools 2017). In 2009 the system undertook its most significant reforms to date, although the genesis of these reforms goes further back. The reforms focused on three areas: opening up the system and the European Baccalaureate to other students, governing arrangements in the system, and cost-sharing amongst the member states.

'Opening up' is the appellation that the Board of Governors has used in all the official documentation relating to the first element of the 2009 reforms of the European schools. This refers to the development of an accreditation procedure for the creation of additional European schools. The accredited national schools are classified as European schools Category II or III, while traditional European schools are classified as Category I. The principal difference between these three types of European schools is that Category II and III schools do not recruit exclusively the children of civil servants, but have been established to spread European schooling to the general population in Europe. The system of governance as well as the system of funding in Category II and III schools also differs from traditional Category I European schools. The principal difference between Category II and III schools is that a Category II European school receives a proportional subsidy from the $\mathrm{EU}$ in relation to the number of children of civil servants attending it. Category II pupils are admitted through a financial agreement between the schools and a number of accredited organisations and companies. In contrast, Category III European schools are in no way dependent on European institutions, except in so far as the Board of Governors forges an agreement with the 
school to certify that the establishment offers European schooling. The distinction between Category II and Category III schools has become less important recently. Category III schools are now referred to as accredited schools.

Category I pupils are in the main children of officials and contract staff (in post for at least one year) of the EU institutions and of the staff of the European schools, and of the European Patent Office in the case of the Munich school. The percentage of pupils belonging to Category I has been steadily increasing in recent years and this category now accounts for $79.8 \%$ of the pupil population (September 2016). The Brussels and Luxembourg schools, where there are large numbers of EU officials and a lack of school places requires a restrictive enrolment policy to be enforced for Category II and III pupils, have a high percentage of Category I pupils, over $90 \%$ in the four Brussels schools (100\% for Berkendael); whereas the schools located in places where the number of EU officials is small have a far lower percentage of such pupils. A new school in Brussels has just been commissioned. Category II pupils account for $4 \%$ of the pupil population, and Category III pupils constitute $16.1 \%$ of the total population. (These figures are as of September 2016.)

The second element of the policy of opening up involves the transformation of the European Baccalaureate. Category II and Category III schools were allowed to offer the same final certificate as Category I European schools. The Baccalaureate is legally recognised in all European universities. Both the system of accredited schools and the process of widening access to the European Baccalaureate are underpinned by the idea that the whole system shares a common pedagogical ethos. We examine the usefulness and sustainability of the examination arrangements made within the system, and point to the conflicting and at times contradictory purposes, learning and accreditation, of the European Baccalaureate in Chap. 5.

This broadening and expanding is based on the idea that the notion of European schooling is a particular, exportable and replicable type of education. This principle is currently operationalised through a centralised system that gives the Board of Governors control over setting, correcting and adapting the common criteria of evaluation. Such criteria were established in 2005 and have been updated periodically. Jacques Delors, the 
former president of the European Commission, once called the European schools 'a sociological and pedagogical laboratory' (Delors 1993). Indeed, the most common adjectives used in the literature to refer to European schools are those of pioneering and experimental.

The second element of the 2009 reforms allowed the granting of more autonomy to Category I schools. This autonomy, referring as it does to pedagogical, administrative and financial arrangements, was designed to allow decisions that can reasonably be taken at school level to be made there, that is, the most immediate level that is consistent with their resolution. This is the principle of subsidiarity and in this context it covers matters such as in-service training, staff development, the use of information and communication technologies, data protection, child protection, transfers provided by the financial regulations and enrolments of pupils. The third element of the reforms referred to new arrangements relating to cost sharing amongst the member states, and in particular, to the costs of the secondment of teachers.

Different writers who have examined the European Schools, such as Shore and Finaldi (2005) and Savvides (2006a, b, c), agree that one of the principal limits of the system is its selective nature. In 2007 the European Parliament requested an extensive analysis of the academic and professional careers of the European schools' graduates and their backgrounds (European Commission 2007a, b). This showed, amongst other findings and unsurprisingly, that some of the traditional European Schools recruited more than $90 \%$ of their student population from the same family background, i.e. European civil servants. In the case of the European schools located in Brussels and Luxembourg the demand from Category I children is higher than the number of places available.

One of the reasons for the exclusive character of the schools is that they subscribe to a particular mission and function. The regulations of the system affirm that 'the setting-up of a European School is [...] justified only when it is vital to ensure the optimum operation of an essential Community [European Union] activity' (Board of Governors 2009: 4). In this sense the criteria for opening new schools are not easily met, and the final decision always depends on the willingness of the member states to initiate the process. Throughout the years there have been many cases where these conditions have been met and yet new schools have not been 
opened, particularly in cities other than Brussels and Luxembourg. The decision to open a new school remains a political decision. The power to establish new European schools is a formal and exclusive competence that only the member states and their national governments have. In other words, the European institutions and the management bodies of the European schools do not have the capacity to open up and extend the system: 'the proposal that a European School be set up on the territory of a Member State is initiated by the State in question' (Board of Governors 2009: 4).

The special character of the schools does not reside exclusively in their European identity, but principally in the fact that they are offering an education based on schooling elements that do not exist at the national levels, such as: early multilingual schooling, a unified curriculum across Europe, a pedagogy based on a pluralistic national perspective, and a multinational student environment. The System's intention is to foster such particularities at the same time as encouraging a sense of European awareness, promoting knowledge about the institutions, their history and a developing sense of citizenship at the European level.

The language policy of the schools has occasioned the most scrutiny (cf. Baetens Beardsmore 1993; Bulmer 1990). European schools are organised in language sections. Students generally speaking receive their education in their native language. The study of a first foreign language (English, French or German), known as L2, is compulsory in each school, from the first year of primary school. In addition, all students must study a second foreign language (L3) from the first year of secondary school. Significantly, the subjects of history, geography and economics (the latter from the fourth year onwards) are studied in the student's first foreign language from the third year of secondary school, instead of in their mother tongue.

The second area of interest has focused on analysing the history and general functioning of the schools (cf. Swan 1996; Shore and Finaldi 2005; Smith 1995). In addition, there are a small number of recent studies that are beginning to offer new lines of investigation, in particular in relation to the study of the European dimension of the system (cf. Savvides 2006a, b, c). We examine this European dimension in more detail in Chap. 4. 
The Category 1 European schools are located in those cities where the European Union has deployed its main administrative bodies. Brussels and Luxembourg have 6 of the 14 Category I European schools, accounting for more than $60 \%$ of the total student population. In order to set up a Category 1 European school, the Board of Governors approved in 2000 the indicative document containing the Critères pour l'ouverture, la fermeture ou le maintien des Écoles Européennes (Board of Governors 2000). Best known in the system by the name of the rapporteur, the Gaignage criteria set a number of conditions that justify politically the creation of a Category 1 European school. The experience since 2000 is that these criteria are not easily met in cities other than Brussels and Luxembourg. For the opening of a Category 1 European school the document mandates that the Board of Governors must take into account three elements: a minimum number of language sections; a minimum number of students per language section; and a minimum number of Category I students. In addition, the initiative for opening a new Category 1 European school has to come from the member state where the school is to be located.

\section{Language}

European schools have to deal with a paradoxical situation. On the one hand the founding principle of the System calls for the establishment of language sections corresponding to the linguistic background of their students. On the other, the Gaignage criteria of 2000 state that there has to be a minimum number of students from the same language background before a corresponding section can be created (Board of Governors 2000). The four European schools in Brussels are examples of schools that have sought to maintain a level of diversity and coherence with their intakes. Consequently, the number of SWALS (Students without a Language Section) has steadily increased since 2007 and for the year 2011-2012 the number rose to 676 , representing approximately $7 \%$ of the total population of the European schools in Brussels (Board of Governors 2011). Since then the number of SWALS shows no signs of decreasing.

Not all European schools offer the same types of language section. A Lithuanian student, for example, will have a restricted choice in Brussels. 
The only school with a Lithuanian section is Brussels II. In some European schools, and for some languages, due to a lack of available students it has not been possible to create specific language sections. The main issue regarding language arrangements in the Category 1 European schools is maintaining a high degree of plurality and diversity of their language sections, while at the same time fulfilling the indicative criteria set by the Gaignage Report in 2000.

Language is the factor that best explains the genesis and evolution of the system. The schools were founded with a particular and specific purpose in mind. Civil servants arriving in Luxembourg in 1953 wanted their children to retain their own cultural heritage. This was achieved by creating a system where the different children could learn in their mother tongue following the same standards as in their country of origin. In that sense the history of the system shows that the principle that governs European schools is language pluralism, not assimilation.

Three langues véhiculaires have a special status: French, German and English. Students have to choose between one of these when they enter the first year of the primary school, and they will keep their langue véhiculaire (L2) until the Baccalaureate. The L2 will not only be a language course, it will become the second working language of each student, since it is compulsory that students attend history and geography classes in the L2 they choose on entry, plus economics from S4 (the fourth level of secondary education) if chosen as an option and, since September 2014, religion or ethics from S3 (the third level of secondary education).

The status of these working languages is a source of academic debate. Swan (1996), for example, suggested over twenty years ago that other European countries such as France, Britain and Germany already have their own network of schools abroad, which offer their children an alternative, if often expensive, source of education where their own native language is the language of instruction. However, some of the smaller member states do not provide such an alternative. Swan's argument consists of defending the idea that the languages that are getting most benefit from the language policy of European schools are precisely the ones that are not véhiculaires. Indeed, the fact that European schools aim to offer language sections in all the languages spoken throughout the European Union, though this can only be realised by a cluster of schools, offers the chance to the parents coming from all the member states to enrol their 
children in their language section, without depending on the setting up of a Polish school or a Spanish school in Brussels. Yet, the offer in terms of diversity is much more limited in practice. None of the European schools include all the language sections for all the official languages of the European Union.

This has created the need to integrate those students who do not have their own language section. Students Without a Language Section (SWALS) have to attend one of the language sections available, while receiving a separate programme in their mother tongue. At primary and secondary levels they only receive one class in their native language, the rest of the courses being taught in the language of the section into which they have chosen to integrate. SWALS are normally enrolled in one of the working language sections. This then becomes their L2. They can also be enrolled in their host country language section, on the condition that no additional costs are involved. Since 2011 Category III pupils have been enrolled with their L1 being the language of their section.

Shore and Finaldi (2005) have also argued in favour of the language policy of the schools. In their study, they suggest that although officially portrayed as a matter of language development, the most noteworthy aspect of this language policy is that the teacher will hardly ever share the same nationality with his or her students. At the heart of this practice seems to be an explicit attempt to separate nationality from the teaching of sensitive subjects such as history or geography. SWALS are only ever taught their L1 by a teacher from their own country. Increasingly, students are taught by teachers from a range of nationalities, as more subjects are taught in L2 and because more non-native teachers have been recruited. Generally however, it should be recalled that the first principle of the European schools is primacy of mother tongue teaching and the system is built round the secondment of teachers from national systems so that in most sections (certainly the non-véhiculaire sections), teachers of core subjects do share the same nationality as their students. Table 1.2 gives an indication of the nationality of the population of students in 2016.

Swan (1996) also looked at the use of the langues véhiculaires as an integral part of the curriculum. He suggested that teaching history to students with other nationalities has the advantage that it provides an 
Table 1.2 Pupil population by nationality and by national populations

\begin{tabular}{lll}
\hline Nationality & Population 2015-2016 (National & \\
\hline population - 1st July 2016) & $\%$ \\
Belgian & $354(8,569,633)$ & 1.3 \\
British & $2737.25(11,371,928)$ & 10.3 \\
Bulgarian & $1314.67(65,111,143)$ & 4.9 \\
Croatian & $442.83(7,097,796)$ & 1.7 \\
Cypriot, inc. North & $121.17(4,225,001)$ & 0.5 \\
Cypriot & $52.17(1,176,598)$ & 0.2 \\
Czech & & \\
Danish & $431(10,548,058)$ & 1.6 \\
Dutch & $531.5(5,690,750)$ & 2.0 \\
Estonian & $920.67(16,979,729)$ & 3.4 \\
Finnish & $264(1,309,104)$ & 1.0 \\
French & $554.42(5,523,904)$ & 2.1 \\
German & $3222.08(64,668,129)$ & 12.1 \\
Greek & $3358.17(80,682,351)$ & 12.6 \\
Hungarian & $989.83(10,919,459)$ & 3.7 \\
Irish & $515.08(9,821,318)$ & 1.9 \\
Italian & $452.5(4,713,993)$ & 1.7 \\
Latvian & $2650.75(59,801,004)$ & 9.9 \\
Lithuanian & $270.33(1,955,742)$ & 1.0 \\
Luxembourg & $372.17(2,850,030)$ & 1.4 \\
Maltese & $241.25(576,243)$ & 0.9 \\
Polish & $74.75(419,615)$ & 0.3 \\
Portuguese & $800.92(38,593,161)$ & 3.0 \\
Romanian & $684(10,304,434)$ & 2.6 \\
Slovakian & $488.17(19,372,734)$ & 1.8 \\
Slovenian & $323(5,429,418)$ & 1.2 \\
Spanish & $210.33(2,069,362)$ & 0.8 \\
Swedish & $2275.58(46,064,604)$ & 8.5 \\
Others & $607.17(9,851,852)$ & 5.3 \\
Total & 1431.25 & 100 \\
\hline Source: Office & 26,691 & $2017)$ \\
\hline
\end{tabular}

Source: Office of the Secretary General of the European Schools (2017)

Note: The figures in this table are not 'round numbers'. A large number of pupils enrolled in the European Schools have more than one nationality. Pupils with dual nationality or more are calculated as shares: dual nationality as $0.5+$ 0.5 , triple nationality as $0.33+0.33+0.33$. 
opportunity to question attitudes held by people in schools, at home or in international schools dominated by the language and culture of that particular country. Yet, when examining the textbooks used in European schools this need to develop a European sensitivity is more a matter for the teacher than the tools available. Textbooks are the same ones that are used in national systems. In that sense it is up to the teachers to develop a specific transnational approach when teaching history and geography, and that it is not just a question of teaching national history in a European context or incorporating historical narratives from all the European Union countries into the syllabus. It is also a matter of developing a genuine multilingual, pluricultural and hermeneutic view of history and history teaching.

Finaldi-Baratieri (2005) points out that the principle of equality of esteem between different languages is more difficult to achieve in practical than in theoretical terms. In her view, the policy of langues véhiculaires illustrates how European schools can be more nationalistic than the official discourse would allow. More interestingly, she argues that the working language policy testifies to, at the micro-level, the force and power exerted by the European Union's core member states. Indeed, the system is imperfect when implementing the policy of equality of esteem between languages. Behind the plurality offered, the reality is much more constrained and limited. And yet, despite the imperfect translation into practice of this theoretical principle as the basis of the multilingual policy of the schools, the educational offer in terms of language diversity remains higher than the offer in the rest of the educational systems in Europe. Despite these problems, the language policy still illustrates something unique: the political will to expand the system to all European languages. We examine in Chap. 3 and in much greater detail the organisation of language learning and the development of intercultural competence in the European School System.

\section{Admission and Access}

Table 1.3 shows the number of pupils for each school and the total numbers registered in the system for the period 2013-2016 and the variation between years. The number of pupils at Brussels 1 is supplemented by 


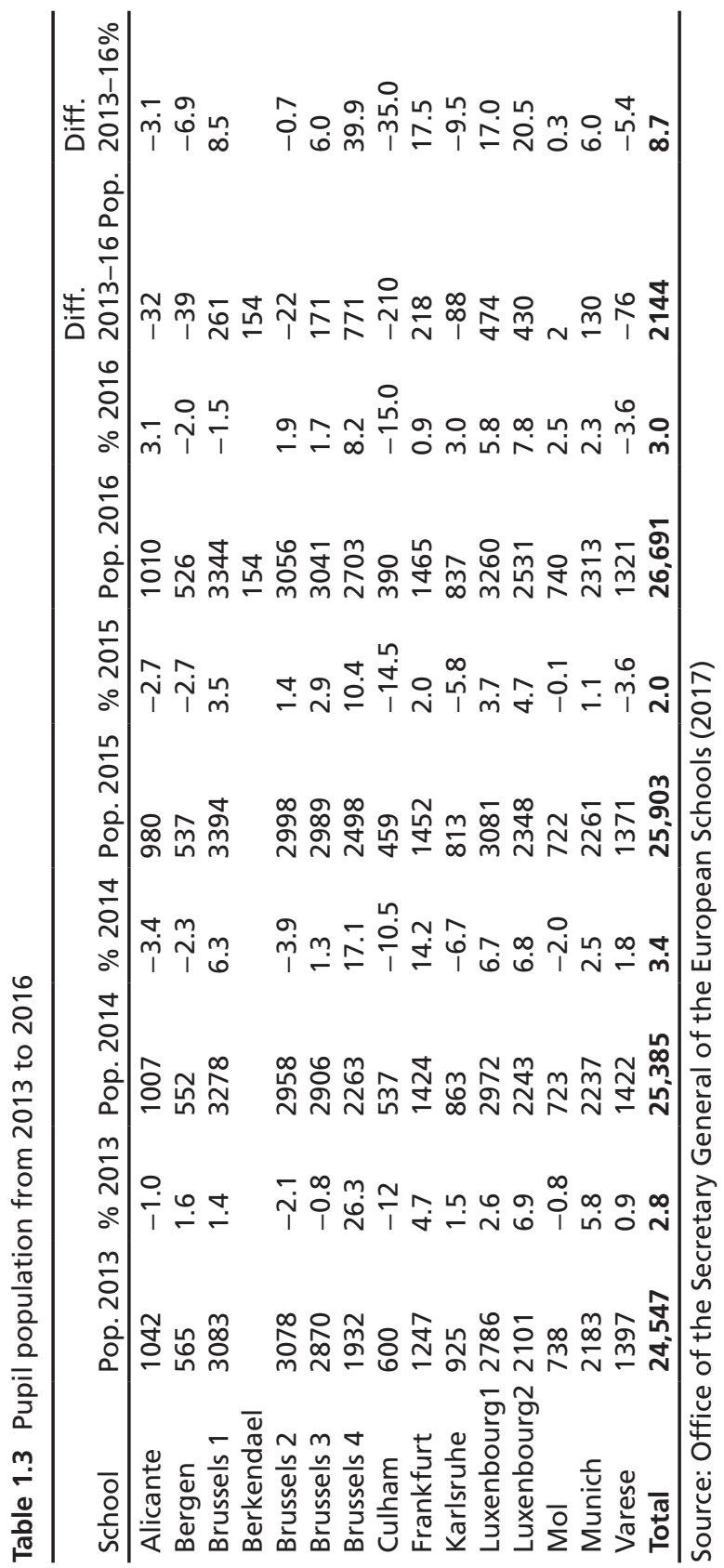


those pupils located at the Berkendael site, as an extension of the main campus. This relocation is temporary, pending the opening of Brussels 5 . These figures do not include associate schools.

The total student population of the European schools (October 2016) was 26,691, and this represents a $3 \%$ growth in comparison with the previous year. $67.7 \%$ of the total student population goes to one or other of the four Brussels schools (46\%) (at the time of writing a new school in Brussels is being opened) and the two Luxembourg schools (21.7\%). The European schools located in Brussels have systematically suffered from a problem of overcrowding for the past ten years.

When faced with the problem of scarcity of places, the Board of Governors has been applying in the last six years a restrictive enrolment policy for Category III students. As indicated in the official enrolment policy for 2013-2014, the enrolment of such students is 'restrict[ed] to the siblings of present students, abiding strictly by the decisions of the Board of Governors concerning this category of pupils' (Board of Governors 2012: 3). This has led to a decrease in the percentage of Category III children in the European schools in Brussels, providing new arguments for the debate about the potential homogeneity of students within the schools. The difficulty with solving the problem of, for example, overcrowding in Brussels, is leading to a major issue of legitimacy. The reforms of 2009 were implemented to 'open up' the system to other children than those in Category I, though accredited schools had been introduced earlier. While the System has started to open up outside the Belgian capital, in the Category 1 European schools the issue relating to the legitimacy of the whole system of admissions has become more acute, and has only been partly solved by the opening of a new school in Brussels.

\section{Schooling}

In 2006 the Board of Governors decided to commission an independent analysis of four of the smaller Category 1 European schools located across Europe. The outcome was the report submitted by the Bureau van Dijk Management Consultants SA in August 2006 (Van Dijk 2006). This 
report included a brief comparative analysis of the European schools and the potential alternatives in terms of international schooling in the four cities studied.

The team of consultants based their conclusions on a series of interviews with the parents, teachers and directors of these four European schools. The Report stated that among the most praised features of the system was that 'comparatively speaking international schools do not offer language tuition as diversified and as intensive as European schools' (ibid.: 13). Two other elements were highly praised by parents: the first of these was the European Baccalaureate, which is 'recognized by nearly all the Member States and therefore allows their children to follow their studies in any European universities' (ibid.: 13); and the second was 'the multicultural and European citizen spirit brought by the multilingual education of European schools, these being certainly not perceivable in the international schools' (ibid.: 14).

This is a home grown system that is sixty years old, and based on a model of an elite European education long superseded by changes in society as well as the Commission itself (not least the growth of the European Union from the original six countries in 1952 to the current twenty-eight countries, though the United Kingdom is at the time of writing seeking to leave the European Union). It is widely agreed that the current system shows signs of inconsistency across different schools and language sections, and that it also shows signs of incoherence. Many students leave the system at ages between 14 and 16 (secondary years $\$ 4$ and S5) when it is reported that the science curriculum, for example, becomes significantly more difficult. There is meant to be a free choice of options for students, but the reality is closer to a fairly loose assemblage of available subjects and options that changes from school to school and from year to year. There is an overemphasis on timetabling allocation of subjects as a proxy for quality and academic difficulty.

Some teaching groups are extremely small due to a number of factors based on taken for granted assumptions about pedagogy that may not be valid. Within the system, parents' perceptions of student identity are very important, as well as the ability to transfer to university. There is some confusion around the role of languages within the system, and a lack of 
consideration given to issues surrounding non-modern foreign language subjects in second and third languages, particularly with regards to the needs of the smaller language sections. There are problems with the European Baccalaureate as a qualification, particularly relating to the use of oral examinations, marking systems, conversion tables and quality assurance systems.

The European schools language policy is embodied above all: in the principle of supporting L1 learning through the creation of language sections; in the provision of additional support for students without a language section; in having students study content subjects through their L2; and by offering L3, L4 and L5 language courses. However, there is no overarching language policy document that guides the co-construction of learning environments that foster bilingualism, trilingualism or multilingualism, though a vision on the use of language is expressed in the Founding Convention and also in the Principles of the European Schools (cf. Office of the Secretary General of the European Schools 2017).

\section{Changing the System}

We also need to make sense of the notion of change or alteration. Objects and relations between objects, educational systems and people change their form over time. An example of this change process at the epistemological level is the invention (insofar as the set of concepts and relations between them is new) of the notion of probability (cf. Hacking 2005) in the nineteenth century, and this changed the way social objects could be conceived and ultimately arranged. Change can occur in four ways: contingent ontological, planned ontological, epistemically-driven ontologi$\mathrm{cal}$, and in the transitive realm of knowledge, epistemological (cf. Scott 2011). With regards to the example above, the invention of probability, two phases of change can be identified. The first is where knowledge is created and thus operates at the epistemological level, the new arrangement of knowledge. The second is where this knowledge has real effects at the ontological level, so that new arrangements, new formations, new assemblages come into being. The dilemma is that the social world, in 
contrast to the physical world, is always in a state of transition and flux, so that it is hard to argue that there are invariant laws by which the world works, at all times and in all places, except in a basic logical and rational sense.

Societies are characterised by notions of continuous emergence, flux and change. Objects in the world cannot be characterised by their essential qualities, but only through their interactions with other objects. Complexity resides in all these various interactions which produce new objects (understood as different forms of structure), and results in a bewildering array of arrangements of material and human objects; and because they are difficult to characterise rarely allow definitive accounts of what is going on to be produced. It is the complexity of these objectinteractions and their subsequent and temporary coalescences that makes it difficult to provide complete descriptions of them. The epistemological level is unsynchronised with the ontological level because researchers and investigators have not developed sufficiently their instruments and conceptual schema for capturing something that is both ever-changing and has too many elements to it, i.e. it is too complex. However, this doesn't categorically rule out the possibility of providing more complete descriptions of events, structures, mechanisms and their relations in the world, and this suggests a notion of human fallibility which means that human actions are corrigible. The twin elements of complexity and temporal emergence cannot preclude correct descriptions being made of activities in the world, only that these elements can create considerable difficulties. This is further compounded by how emergence operates in the world.

Many theorists go further than this (for example, Osberg and Biesta 2007), and hold to a version of emergence in which there is a radical incommensurability between different formations over time (whether material, embodied or discursive). Furthermore, it is impossible to predict what inter-connections, new formations, and iterations of the objectsystem will be realised because the principles of the new mechanism are not given in the current arrangements. In other words, the relations between objects and the objects themselves, which make up activity systems, are not patterned in any meaningful sense; there is a radical incommensurability between these different iterations. 
All discussions of a person or an education system over time require some understanding of change; that is, the notion of change is built into the conception of the human being or system. There is also the problem of persistence. If there was no cohering element between time moments, so that every moment entails a change of person or system, we would not have a sense of personhood or system identity, which therefore has to include a notion of persistence over time, and, in addition, has a notion of emergence. And this is emergence understood in its two modes: as a temporal phenomenon and ontologically as a response to the stratified nature of reality.

Insight into problems faced by an education system and awareness of potential solutions do not necessarily lead to the ability to act in an effective manner in order to guide stakeholders in instituting a change. The rapid and successful implementation of reforms in a school system is directly dependent on the quality of the knowledge, skills and thinking that a system and those that introduce its planned reforms bring to the reform process. Moreover, innovations and reforms call for new and often substantially improved, knowledge, skills and thinking in several domains. This includes knowledge about obstacles to change at both the instrumental and affective levels and about the change process itself.

Michael Fullan (2001) suggests a number of strategies for reforming an education system: maintaining a focus on moral purpose; understanding the change process; increasing coherence among various aspects of a planned change; relationship-building; knowledge creation and sharing; and building commitment among an organisation's internal and external members (stakeholders). Fullan focuses on consciously being aware of, shaping and using the ideational realm of aspirations, commitments and values, as well as on the mechanics of how people work together, create and manage knowledge.

However, despite what is known about educational change, it is noteworthy that education systems and their institutional arrangements are stubbornly resistant to change'. Argyris (2010) goes even further arguing that organisations and their leaders tend to be trapped in the status quo and in their own behaviours. These behaviours are often characterised by a tendency to blame others, and self-deception and rationalisations. Similarly, Kegan and Lahey (2009) identify a com- 
mon malaise of immunity to change at both the individual and institutional levels. Two central messages about overcoming resistance to change rise out of the work of leading thinkers in change management. The first is that those leading change require high levels of meta-cognitive, meta-affective and meta-social awareness. The second is that people arrive at work with their personal understandings and feelings, and that these need to be explored in relation to work in order to understand their impact on the work process. In other words, change in the workplace almost always requires more than mechanical or technical solutions. Whatever changes are sought, usually these also need to lead to a change in beliefs, feelings, knowledge and behaviours, if this change is to be sustainable.

To move beyond purely mechanistic solutions, Kegan and Lahey (2009) argue that this requires the identification of those assumptions that are driving decision-making. Assumptions are something we take as being true without thorough investigation. For example, if a stated organisational commitment is to distribute leadership in order to ultimately improve student learning, a leader may still not delegate sufficiently because he or she does not wish to lose control. He or she may believe that holding onto control is a way of maintaining standards. Until that underlying assumption is challenged through analysis, and the development of a belief in the capacity of others to lead, substantial change will not take place. Kegan and Lahey (ibid.) propose that individuals need to be supported in exploring their own individual immunity to planned changes, and that the institution needs to explore its collective immunity to the desired or planned change. Without challenging underlying assumptions at both the personal and institutional level, it will be difficult for an organisation to institute change.

One of the most important change mechanisms is political and we will examine this type of mechanism in greater detail in the chapters that follow: the curriculum in Chap. 2; the role of languages in the system in Chap. 3; European nationalism and schooling in Chap. 4; assessment reforms of the system in Chap. 5; external relations with other systems of education such as the various European higher education systems in Chap. 6; and, most importantly, cosmopolitan and European conceptualisations of schooling in the last chapter. 
A team of researchers from UCL Institute of Education, a constituent college of the University of London, which included the authors of this book, carried out the research for this project during the academic year 2014-2015, as part of a European Commission funded evaluation project looking specifically at the upper secondary phase of education in the European Schools System. During this time we spoke to representatives of all the stakeholder groups, including students, teachers and parents, as well as key senior figures in the Office of the Secretary General, and the European Commission. We also visited different European Schools and sat in on meetings. We carried out significant amounts of desk research, and reviewed internal documents (cf. Leaton Gray et al. 2015). In the next chapter, we examine the curriculum of the European Schools and how this has changed during the life history of the system.

Open Access This chapter is licensed under the terms of the Creative Commons Attribution 4.0 International License (http://creativecommons.org/licenses/ by/4.0/), which permits use, sharing, adaptation, distribution and reproduction in any medium or format, as long as you give appropriate credit to the original author(s) and the source, provide a link to the Creative Commons license and indicate if changes were made.

The images or other third party material in this chapter are included in the chapter's Creative Commons license, unless indicated otherwise in a credit line to the material. If material is not included in the chapter's Creative Commons license and your intended use is not permitted by statutory regulation or exceeds the permitted use, you will need to obtain permission directly from the copyright holder.

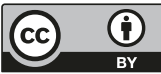

